\title{
La función constitucional de los tributos: especial referencia a la función redistributiva y su relación con la justicia tributaria
}

\author{
Nataly Patricia Montesinos León \\ Facultad de Ciencias Contables, Universidad Nacional Mayor de San Marcos, Perú
}

\section{Resumen}

El presente artículo analiza la función constitucional de los tributos, su evolución histórica y su relación con la justicia social en el marco de un Estado social y democrático de derecho. Se intenta demostrar que un sistema tributario será justo cuando integre la justicia en la tributación y la justicia distributiva en el gasto, a través de la distribución de los recursos obtenidos mediante el gasto público. De cumplir con esas condiciones, se cubrirán las necesidades asumidas por el Estado social y democrático de derecho.

Palabras clave: función constitucional, tributos, redistributiva, recaudatoria, justicia social

\section{The constitutional function of taxation: special reference to the redistributive function and its relationship with taxation justice}

\begin{abstract}
This article analyzes the constitutional function of taxation, their historical evolution and their relationship with social justice in a social and democratic state. It's trying to demostrate the premise that a taxation system will be fair, when integrating justice in the taxation and distributive justice in government spending, through the distribution of the resources obtained, through public expenditure, to cover the needs assumed by the social and democratic state.
\end{abstract}

Keywords: constitutional function, taxation, redistributive, collection, social justice 


\title{
A função constitucional dos impostos: referencia especial a função de redistribuição e sua relação com a justiça fiscal
}

\begin{abstract}
Resumo
Esta publicação analisa a função constitucional dos impostos, sua evolução histórica e sua relação com a justiça social no marco de um Estado social e democrático de direito. Tentamos provar a premissa de que um sistema tributário será justo, quando integra a justiça na tributação e justiça distributiva nos gastos através da distribuição de recursos obtidos, através de gastos públicos, para cobrir as necessidades assumidas pelo Estado social e democrático de direito.
\end{abstract}

Palavras-chave: função constitucional, impostos, redistribuição, cobrança, justiça social.

\section{Introducción}

El presente artículo busca efectuar un análisis de la función constitucional de los tributos. Para ello, se inicia con el estudio de la evolución histórica, desde su primera concepción hasta el momento de su incorporación constitucional en función de los fines del Estado social de derecho.

A lo largo de los apartados del presente artículo, se puede observar cómo se parte de una noción únicamente instrumental de los tributos, como medios recaudatorios, hasta llegar a su función redistributiva. Esta, dentro del modelo del Estado social de derecho, resulta implícita, en tanto que, a partir de su utilización, se busca la equitativa distribución del ingreso.

Finalmente, se analiza cómo la función redistributiva presenta una íntima vinculación con la justicia distributiva. En principio, esta última se encuentra relacionada con la forma en la que se distribuye la carga tributaria y, en segundo lugar, con el modo de distribución de la riqueza entre los contribuyentes, asociado a razones de justicia social.

\section{Metodología}

Se parte de un enfoque cualitativo. De este modo, se intenta valorar las cualidades de la función constitucional de los tributos mediante la técnica de análisis de legislación comparada y el análisis de la jurisprudencia del Tribunal Constitucional.

\section{Evolución histórica de los tributos}

Como antecedentes históricos de la utilización de los tributos, se considera el im- 
puesto al aceite establecido en el antiguo Egipto, recaudado por lo escribas; el impuesto conocido como eisfora, establecido en la antigua Grecia en los tiempos de guerra, que era usado para pagar gastos generados por el contexto bélico; los impuestos denominados portoria, establecidos como derechos de aduana de importación y exportación en la antigua Roma; entre otros. Como se puede apreciar, la utilización de los tributos data de épocas remotas, desde las que ya se reconocía como la forma de financiamiento más utilizada por los gobernantes. No obstante, si bien su utilización es antigua y generalizada, el fundamento de la imposición ha evolucionado a través de la historia desde una imposición arbitraria a una limitada por principios y derechos.

En las primeras civilizaciones, la imposición de los tributos no obedecía a razones equitativas; por el contrario, la mayoría de las veces, estaba basada en los caprichos de los gobernantes frente a los cuales no se poseían derechos, sino únicamente deberes, lo que produjo el sometimiento de las clases menos favorecidas.

El primer antecedente de la imposición de límites a la creación de tributos se presenta en la Carta Magna de Inglaterra (1215), en la cual se limitaba al rey Juan "sin Tierra" a establecer imposiciones solo con el consentimiento de los representantes del pueblo. Sin embargo, el concepto de "pueblo" prestaba mayor importancia a las personalidades importantes, tales como arzobispos, obispos, abates, condes y barones, cuya voluntad imperaba sobre la del pueblo mismo.

Posteriormente, como consecuencia de los cambios políticos y sociales desencadenados por las ideologías libertarias y democráticas de los precursores de la Revolución francesa, obras como El Espíritu de las leyes o el Contrato Social consagrarían la idea de legitimidad de los tributos. En este sentido, como resultado de la revolución, el principio de legalidad en materia tributaria, que lleva implícito el concepto de legitimidad de los tributos al ser expedidos por los representantes del pueblo, fue consagrado en la Declaración de los Derechos del Hombre y del Ciudadano, en su artículo VI, el cual presenta el concepto de la representatividad, es decir, el derecho de los ciudadanos a colaborar en la formación de las leyes a través de sus representantes. Además, esta declaración contiene un apartado relacionado al financiamiento estatal y reconoce, en su artículo XIII, la necesidad de imponer una contribución común a todos los ciudadanos para sostener la fuerza pública y los gastos de administración.

Por su parte, el Derecho Tributario como disciplina jurídica se puede identificar, por primera vez, en la promulgación de la Ordenanza Alemana de 1919. Con este instrumento, se da inicio al desarrollo de los principios doctrinales de la imposición tributaria.

Dicho esto, si bien la consagración del principio de legalidad tributaria es el punto de partida de la legitimidad de las imposiciones tributarias, a partir del desarrollo de la disciplina del Derecho Tributario, se estableció que la creación de leyes debe observar, además, otros principios tributarios, como el de proporcionalidad, equidad, generalidad, capacidad contributiva, reserva de ley, entre otros, que, junto al carácter redistributivo del gasto público, constituyen el primer marco de justicia tri- 
butaria.

Finalmente, es importante resaltar, en cuanto a la justicia tributaria, que, en la actualidad, la distribución de la carga impositiva se concibe no solo cuidando la legitimidad de las leyes, sino también atendiendo los criterios de equidad y de bienestar general.

\section{La función constitucional recaudatoria de los tributos}

Para cumplir con sus funciones, el Estado debe contar con los medios económicos necesarios, ingresos que pueden originarse de diferentes maneras, sean por privatizaciones, actividades empresariales, entre otros, siendo la mayor fuente de dichos recursos aquellos obtenidos del patrimonio de los particulares, en forma coactiva, a través de los tributos.

Pérez (1993) entiende al tributo "como una prestación pecuniaria de carácter coactivo impuesta por el Estado u otro ente público con el objeto de financiar gastos públicos", y precisa que las notas características del tributo son fundamentalmente "la coactividad y el carácter contributivo", aquello que diferencia a los tributos de otras prestaciones, como las multas o sanciones pecuniarias, que, pese a ser igualmente coactivas, carecen de esta finalidad (p.33). Además, el autor resalta la finalidad recaudatoria del tributo como un elemento propio en relación a otras categorías o instituciones jurídicas. Por tanto, se puede considerar que la finalidad principal de los tributos es la obtención de recursos para el sostenimiento del gasto público. En este sentido, la actividad del Estado dirigida a la imposición coactiva de contribuciones pecuniarias nace de la necesidad de obtener fondos para realizar sus fines, lo que constituye el fundamento de la función recaudatoria del tributo.

Atendiendo estas ideas, se puede señalar que la finalidad básica de los tributos es la recaudación, toda vez que han sido, desde su inicial concepción, un mecanismo para obtener recursos que permitan afrontar ciertas necesidades. Así, en muchas acepciones del concepto tributo, subyace intrínsecamente su aspecto recaudatorio, aspecto que, si bien no es el único, ha sido reconocido como un elemento primordial en su configuración. En esta línea, se encuentra la definición establecida por Giannini (1994) sobre el impuesto, la cual señala que es "una prestación pecuniaria que un ente público tiene derecho a exigir en virtud de su potestad de imperio, originaria o derivada, en los casos, en la medida y según los modos establecidos en la ley, con el fin de conseguir un ingreso" (p.46).

Por lo mencionado, es posible afirmar que el tributo resulta esencial para el funcionamiento del aparato estatal, en tanto que el Estado requiere de un sistema tributario eficiente y suficiente, que garantice el sostenimiento del gasto público y la realización de sus fines. Asimismo, en relación a su finalidad recaudatoria, se debe considerar el principio de capacidad contributiva, como un parámetro en el que se basa la imposición coactiva del Estado, debido a que toda imposición debe estar subordinada a la capacidad económica de los ciudadanos. 
Finalmente, resulta importante señalar que el fin recaudatorio de los tributos no es único ni exclusivo, puesto que también existen tributos creados con fines no recaudatorios, los cuales buscan "fines parafiscales", como defender el medio ambiente, desalentar actividades lesivas para el interés público, entre otros.

\section{La función constitucional redistributiva de los tributos}

Como señala el profesor Lejeune (1980), el tributo "no se agota en una función recaudadora, sino que, en cuanto institución constitucional, tiene un papel que cumplir al servicio del programa y los principios constitucionales" (p. 121). Esta idea permite evidenciar que, adicionalmente a la función de recaudación, la finalidad del cobro de los tributos es el sostenimiento del gasto público, lo cual resulta imperioso, en tanto que el gasto tiende a la satisfacción de las necesidades públicas que dan nacimiento al Estado y justifican su existencia.

El Tribunal Constitucional ha definido el poder tributario dentro de un Estado social de derecho de la siguiente manera:

"Surge así el tributo como presupuesto funcional del Estado social, considerando las características del mismo: (...) Por un lado, su capacidad productiva y su flexibilidad, que le permite adaptarse a las necesidades financieras de cada momento, y lo convierten en un instrumento crucial para afrontar las crecientes necesidades financieras del Estado social. Por otro lado, su aptitud para producir un efecto de redistribución de rentas compatible con los derechos y libertades constitucionales, al permitir detraer mayores recursos económicos de las economías privadas más favorecidas, y menos (o incluso ninguno) de las menos favorecidas" (Expediente $\mathrm{N}^{\circ}$ 03797-2006-AA, 2007).

En el criterio anterior, se encuentra contenida la función redistributiva de los tributos, en tanto que, como lo señala el Tribunal Constitucional, estos no solo se constituyen como el medio de contribución al sostenimiento de los gastos públicos, sino también como el criterio para proceder a su reasignación. Así, en el modelo actual, el Estado busca proporcionar a sus ciudadanos un mínimo indispensable para su subsistencia y garantizarles una adecuada calidad de vida, fin que se logra a través de la asignación equitativa de los recursos públicos mediante la administración del gasto público.

Como se ha mencionado en el apartado anterior, el financiamiento estatal a través de la imposición tributaria emplea como parámetro a la aptitud económica del contribuyente, entendida como el principio de capacidad contributiva. Este principio también se encuentra vinculado a la función redistributiva del tributo, en tanto que sirve como criterio para exigirle, en mayor medida, a aquellos que poseen más riqueza en comparación con otros y, de esa forma, utilizar lo recaudado en prestaciones que generen oportunidades a los menos favorecidos.

Lo señalado anteriormente encuentra proximidad con la justicia distributiva. Como se mencionó en la introducción, esta se relaciona con dos nociones: primero, con la 
forma en la que se distribuye la carga tributaria y, en segundo lugar, con el modo de distribución de la riqueza entre los contribuyentes, asociado a razones de justicia social.

Ahora bien, cierto sector de la doctrina señala que, dentro de la lógica del Estado social, se debe preferir los impuestos que, tradicionalmente, cumplen mejor los principios de justicia tributaria, es decir, aquellos de carácter directo y personal, pues son los más efectivos para el cumplimiento de los fines y objetivos de este modelo de Estado. Si bien lo señalado resulta esencial en la configuración del sistema tributario, es también importante recoger lo manifestado por Rodríguez (1983), quien señala: "La función de redistribución de la renta se cumple también, con mayor eficacia, mediante un sistema de gasto público, que a través del sistema fiscal, por muy justo y muy progresivo que aparezca configurado en las leyes, pues, en el mejor de los casos, consigue ser proporcional, pero nunca progresivo" (págs. 82 y 87).

En razón de lo indicado, se puede concluir que la función redistributiva de los tributos se verá concretada tanto desde la perspectiva de un sistema tributario justo y progresivo (basado en impuestos directos y personales) como en la efectiva asignación de los recursos públicos (a través de transferencias directas, programas sociales, entre otros), entendiendo que el gasto es una herramienta de la política fiscal que busca mejorar la distribución del ingreso y estableciendo mecanismos que permitan evaluar la eficiencia del gasto acorde con los resultados obtenidos. En este sentido, a juicio de la autora, reconocer expresamente en la Constitución el principio de justicia material del gasto público importaría un criterio material de justicia en la distribución y ejecución del gasto público. Asimismo, constituiría una garantía de los ciudadanos respecto de la eficiencia en la asignación de los recursos.

\section{La función redistributiva y la justicia social}

Como se señaló en el apartado anterior, los tributos no solo constituyen el medio de contribución al sostenimiento de los gastos públicos, sino también el medio para proceder a la reasignación de la riqueza, fundamento sobre el cual descansa la función redistributiva. En torno a tales consideraciones, se enmarca la actividad financiera del Estado, donde los recursos obtenidos serán destinados a cubrir, mediante el gasto público, las necesidades asumidas por el Estado social y democrático de derecho. De esta manera, los tributos son los medios para satisfacer el programa de gobierno, el que busca, como fin último, crear los supuestos sociales de la misma libertad para todos, es decir, suprimir la desigualdad social (Böckenförde, 2000). En este sentido, es esencial agregar que la función redistributiva se enmarca dentro de un modelo de Estado como uno social de derecho, cuya concepción considera implícitamente a la función redistributiva, a partir de la cual se busca la igualdad material.

\subsection{El Estado social de derecho}

Como consecuencia de la Revolución francesa, se establece como forma de Estado, 
el Estado liberal, modelo a través del cual se buscaba el bienestar de los súbditos mediante un marco general en el que el mercado y el individualismo contarían con un rol fundamental. Este modelo consideraba como valores básicos a la propiedad individual, la igualdad en sentido formal, la seguridad jurídica y la participación de los ciudadanos en la formación de la voluntad general estatal a través del sufragio. Dichos derechos se demandaron garantizar mediante un documento escrito denominado "constitución", que, en síntesis, buscaba regular y controlar la actividad estatal a través del derecho, siempre y cuando la ley fuera expresión de la voluntad general, y estuviera orientada a la defensa de los derechos y libertades de los ciudadanos.

Además, una premisa importante en este modelo de Estado era la idea de que las leyes naturales de la economía política determinarían que la búsqueda sin trabas del beneficio privado redundaría en el bienestar general. Por consiguiente, la intervención del Estado en relación con la justicia social era innecesaria, impertinente e inconveniente.

Sin embargo, las grandes crisis económicas del capitalismo, como la producida en 1929, demostraron que el modelo liberal ocasionaba la producción de los desequilibrios sociales. De este modo, tras resultar necesaria la intervención del Estado, surgió un nuevo modelo, el Estado social de derecho.

Tal como señala García (1991): "El Estado social o Estado del bienestar surge tras las dos guerras mundiales, fundamentalmente como una manera de llevar a cabo un orden social más justo e igualitario" (p. 1597). Por su parte, el Estado social de derecho añade una acción social que debe ser desarrollada por el Estado: procurar la provisión de los servicios públicos y prestaciones sociales con el fin de garantizar cierto nivel de cobertura de las necesidades básicas de la población.

Dentro del Estado social de derecho, los tributos son utilizados para la consecución de los fines sociales del Estado, puesto que, si bien el sistema tributario se diseña con la finalidad de asegurar una fuente de ingresos, cobra gran importancia que dichos ingresos sean debidamente redistribuidos. En consecuencia, una de las principales funciones del Estado social constituye que los gastos públicos sean repartidos de forma equitativa para satisfacer con ellos las prestaciones sociales.

Ahora bien, la Constitución peruana, en su artículo 43, recoge la concepción del Estado nacional como uno social y democrático de derecho. En este modelo, la función de los tributos referida al financiamiento de los servicios públicos o los gastos del aparato estatal no es única, dado que también distribuye la riqueza con equidad y solidaridad en el ámbito de la comunidad. De este modo, es posible señalar que las principales funciones del tributo se resumen en recaudar y redistribuir.

Finalmente, cabe precisar que, dentro de este modelo de Estado, resulta fundamental establecer una fuente de financiamiento para la consecución de los fines redistributivos. Esta fuente está constituida por el sistema tributario, siendo los tributos los principales instrumentos para lograr el sostenimiento del gasto público. En esta necesidad estatal, encuentra su justificación legítima el deber de contribuir y la re- 
distribución equitativa del ingreso.

\subsection{El deber de contribuir}

A partir de la Revolución francesa, se reconocieron constitucionalmente deberes a cargo de los ciudadanos, deberes como el de servir a la sociedad, obedecer las normas, entre otros. Si bien, en un principio, la constitucionalización de estos deberes era considerada meramente enunciativa, en la actualidad, y con el tránsito al Estado constitucional, todos los preceptos constitucionales cuentan con la condición de norma jurídica, por lo que son prestaciones exigibles. Dentro de esta conceptualización, se encuentra el deber de contribuir, entendido como el deber de todo ciudadano de colaborar con el sostenimiento del gasto público.

En el Perú, el deber de contribuir no presenta un reconocimiento expreso en la Constitución. Sin embargo, tal y como lo señaló el Tribunal Constitucional en el Expediente № 2727-2002-AA/TC, constituye un principio constitucional de carácter implícito.

Ahora bien, es fundamental señalar que el deber de contribuir se encuentra íntimamente relacionado con el principio de solidaridad, principio entendido como aquel en virtud del cual la sociedad debe colaborar con el financiamiento de la actividad estatal para que este pueda atender las demandas sociales, sobre todo de los sectores más pobres de la población. En este sentido, como señala Rodríguez (2005): "Los deberes públicos, por contraposición a los derechos, son aquellas situaciones pasivas o de sujeción que se imponen a un sujeto para tutelar intereses que no son particulares suyos, sino en beneficio del interés general de la comunidad" (p. 21). Asimismo, es importante replicar lo mencionado por Pauner (2000): "la conexión entre el deber de contribuir al sostenimiento de los gastos públicos y el principio de solidaridad resulta innegable, toda vez que el cumplimiento o incumplimiento del deber de tributar beneficia o perjudica, respectivamente, a todos" (p. 83).

De lo señalado en los párrafos anteriores, se puede concluir que la noción del tributo encuentra su fundamento constitucional tanto en el deber de contribuir como en el principio de solidaridad, puesto que los tributos, además de ser una fuente para la obtención de recursos para financiar los gastos públicos, pueden servir como instrumento para lograr una equitativa distribución del ingreso.

Si bien el deber de contribuir y el principio de solidaridad sustentan la imposición tributaria, estos poseen como límite la capacidad contributiva, que constituye un elemento fundamental en el sistema tributario. De esta manera, incluso cuando no se recoja expresamente en la constitución (como es el caso peruano), debe observarse, en tanto que constituye un componente sustancial en el concepto constitucional del tributo. Dicho de otro modo, resulta evidente la clara correlación entre el deber de contribuir y la capacidad contributiva, en la medida en que esta última es un límite a la potestad tributaria del Estado y un rasgo definidor de la justicia tributaria, así como afecta la posición del ciudadano tanto como deudor frente al Estado como en su condición de destinatario de las prestaciones públicas. 
Finalmente, cabe destacar que el deber tributario fundado en la solidaridad exige la colaboración de todos los ciudadanos para el sostenimiento del Estado, es decir, para que este cumpla con uno de sus fines primordiales, el de redistribuir la renta y la riqueza.

\subsection{La redistribución del ingreso y la justicia social}

Conforme lo señala Landa (2006), la función constitucional de los tributos "radica, por un lado, en permitir al Estado financiar el gasto público dirigido a cumplir con los servicios básicos que la sociedad requiere; $y$, de otro, en la realización de valores constitucionales como el de justicia y solidaridad" (p. 251). En otras palabras, existe una íntima conexión entre los tributos y el gasto público, dado que, a través de los tributos, no se busca únicamente financiar los servicios públicos, sino también distribuir la riqueza. De este modo, se encuentra el correlato del deber de contribuir en la equitativa distribución del ingreso.

En el derecho comparado, el principio redistributivo se encuentra positivizado en la Constitución española, que lo ha recogido en su artículo $31^{\circ}$ numeral 31.2. En este, se establece que el gasto público realizará una asignación equitativa de los recursos públicos, mientras que su programación y ejecución responderán a los criterios de eficiencia y economía.

Ahora bien, este principio constitucional de justicia en el gasto implica una garantía a los ciudadanos respecto de la distribución y ejecución del gasto público, puesto que representa una prohibición del gasto injusto, incluido el gasto arbitrario, que será aquel que contradiga los fines sociales y económicos que persigue el Estado. Sobre este punto, señala Sainz (1977):

"El reconocimiento constitucional de la función redistributiva del Estado obedece a la constitucionalización de la justicia financiera en sus dos vertientes: por un lado, por el principio de capacidad económica o de capacidad contributiva, esto es, el principio de justicia tributaria o fiscal; $y$, por otro, por el principio de asignación equitativa de los recursos, esto es, la justicia en el gasto público" (p. 18).

Asimismo, resulta acertado lo señalado por Rodríguez (1992), en el sentido que "la igualdad y la justicia reales y efectivas suponen no solo tomar en consideración el modo en que se reparte la carga tributaria, es decir, si el sistema fiscal es justo o no, sino que implica tomar en consideración también el destino de los ingresos obtenidos a través del sistema fiscal" (p. 17).

En relación a la distribución equitativa de los ingresos, resulta importante el concepto de cohesión social, que busca fomentar el acceso a mejores condiciones de vida mediante los servicios de educación, oportunidades de empleo, servicios de salud pública, entre otros. Así, este es un indicador de desempeño respecto de la función redistribuidora del Estado.

Además, es preciso señalar que los objetivos de la política redistributiva se sintetizan en la búsqueda de la seguridad económica, y en la reducción de la desigualdad 
económica y social, mediante la intervención del Estado en beneficio de los grupos sociales más desfavorecidos para lograr su integración social. Por lo tanto, el reparto equitativo debería suponer la eficiencia en la gestión del gasto de los recursos por parte del Estado, eficiencia que supone que las necesidades públicas sean tomadas en consideración y que se realice su satisfacción. Este también deberá atender al criterio de economía, que exige alcanzar el mayor número de resultados con el menor número de recursos, lo que, en el contexto social, se traduce como un mayor ámbito de actuación por parte del Estado.

Finalmente, considerando la justicia y la adecuada redistribución, se recomienda optar por tributos progresivos a fin de lograr la progresividad del sistema tributario en su conjunto, en la medida en que resulta el medio técnico a través del cual se pueden alcanzar los fines distintos al recaudatorio. No obstante, es necesario mencionar que, si bien la progresividad es recomendada, no resulta obligatoria para todos los impuestos, pese a que esto sí ocurre con la generalidad, la igualdad y la capacidad económica, dependiendo enteramente de la voluntad del legislador, su observancia en la configuración de los tributos. En este sentido, un sistema tributario será justo no únicamente en tanto sea progresivo, sino cuando integre, además, la justicia tributaria con la justicia distributiva en el gasto.

\section{Conclusiones}

- Desde la antigüedad, los tributos han sido la forma de financiamiento más utilizada por los gobernantes; sin embargo, el fundamento de su imposición ha evolucionado a través de la historia, tras ser utilizado, muchas veces, por los caprichos de los gobernantes, frente a los cuales no se poseían derechos, sino únicamente deberes, hasta ser un instrumento para lograr el sostenimiento de los gastos públicos y la redistribución de la riqueza.

- La concepción actual de los tributos se origina en la consagración del principio de legalidad tributaria, que es el punto de partida de la legitimidad de las imposiciones tributarias y que se sustenta en el concepto de la representatividad.

- Si bien los tributos poseen una función recaudatoria, su imposición presenta como límite al principio de capacidad contributiva, entendiendo este principio como un parámetro sobre el que se basa la imposición coactiva del Estado, debido a que toda imposición debe estar subordinada a la capacidad económica de los ciudadanos.

- Con el surgimiento del Estado social de derecho, la actividad financiera del Estado busca establecer una fuente de financiamiento para la consecución de los fines redistributivos. Esta fuente está constituida por el sistema tributario, en el que el tributo se considera el principal instrumento para lograr el sostenimiento de los gastos públicos y satisfacer el programa de gobierno, que busca, como fin último, suprimir la desigualdad social.

- La concepción del Estado como uno social de derecho presenta, de manera implí- 
cita, una función redistribuidora, a partir de la cual se busca la igualdad material, encontrándose como correlato el deber de contribuir, la equitativa distribución del ingreso.

- El Tribunal Constitucional ha señalado que los tributos no solo constituyen el medio de contribución al sostenimiento de los gastos públicos, sino también el criterio para proceder a su reasignación, lo que otorga al tributo una función redistributiva. Esto no involucra necesariamente la entrega de lo recaudado a los que menos poseen a costa de aquellos con mayor riqueza, sino que los recursos sean invertidos en la realización de obras o prestaciones que generen oportunidades y condiciones de desarrollo económico y social para los ciudadanos menos favorecidos.

- Los objetivos de la política redistributiva se sintetizan en buscar la seguridad económica, reducir la desigualdad económica y social, y reducir la pobreza, por lo que el Estado debe intervenir en beneficio de los grupos sociales menos favorecidos con el objeto de lograr su integración social.

- Un sistema tributario será justo cuando integre la justicia en la tributación y la justicia distributiva en el gasto.

\section{Recomendaciones}

- El sistema tributario debe basarse, en su mayoría, en impuestos directos y personales, que aseguren su progresividad. Asimismo, debe establecerse la efectiva asignación de los recursos públicos a través de transferencias directas o programas sociales, y mecanismos que permitan evaluar la eficiencia y eficacia del gasto acorde con los resultados obtenidos.

- A juicio de la autora, la Constitución nacional debe incluir el principio de justicia material del gasto público, toda vez que ello importaría un criterio material de justicia en la distribución y ejecución del gasto público, lo que constituiría, además, una garantía de los ciudadanos respecto de la eficiencia en la asignación de los recursos.

\section{REFERENCIAS BIBLIOGRÁFICAS}

Böckenförde, E. (2000). Estudios sobre Estado de derecho y democracia. Madrid, Editorial Trotta.

Duran Rojo, L. (2006). Temas de Derecho Tributario y Derecho Público. Libro Homenaje a Armando Zolezzi Moller. Lima, Palestra Editores.

García Pelayo M. (1991). Obras completas. Madrid, Centro de Estudios Constitucionales.

Giannini, A. (1957). Instituciones de Derecho Tributario. Traducción por Fernando 
Sainz de Bujanda, Vol I. Madrid, Editorial de Derecho Financiero.

Landa Arroyo, C. (2006). Jurisprudencia y Doctrina Constitucional Tributaria. Lima. Centro de Estudios Constitucionales y Gaceta Jurídica.

Lejeune Valcarcel, E. (1980). Aproximación al principio constitucional de igualdad tributaria, en Seis Estudios sobre Derecho Constitucional e Internacional Tributario. Madrid, Ed. Edersa.

Pauner Chulvi, C. (2000). El deber constitucional de contribuir al sostenimiento de los gastos públicos. (Tesis Doctoral). Universitat Jaume I, Castellón de la Plana, Comunidad Valenciana, España.

Pérez Royo, F. (1994). Derecho Financiero y Tributario - Parte General, Madrid, Editorial Civitas S.A.

Rodríguez Bereijo, A. (1983). La Constitución de 1978 y el modelo de Estado: consideraciones sobre la función de la Hacienda Pública. Revista Sistema, 53. 82-87.

Rodríguez Bereijo, A. (1992). El sistema tributario en la Constitución (Los límites del poder tributario en la jurisprudencia del Tribunal Constitucional). Revista Española de Derecho Constitucional 36, 17.

Rodríguez Bereijo, A. (2005). El deber de contribuir como deber constitucional: Su significado jurídico. Revista Española de Derecho Financiero, 125. 21.

Sainz De Bujanda, F. (1977). Sistema de Derecho Financiero. Madrid, Universidad Complutense de Madrid.

Tribunal Constitucional (2007). Expediente № 03797-2006-AA, Sentencia: 05 de marzo de 2007. Consultado el 21 de marzo de 2018. Recuperado de:

https://tc.gob.pe/jurisprudencia/2007/03797-2006-AA.pdf

Fecha de recepción: 31/10/2018

Fecha de aceptación: 21/11/2018

Correspondencia: paty4786@gmail.com 